\title{
Benzene-Poly-Carboxylic Acids Complex with Cis-Diammineplatinum (II) Dichloride in the Treatment of Stage IV Breast Cancer Patients
}

\author{
Sagita Dewi ${ }^{*}, 1$, Stig Larsen ${ }^{1}$, Vichien Srimuninnimit ${ }^{2}$, Yen-Shen $\mathrm{Lu}^{3}$, Tjakra Manuaba ${ }^{4}$ and \\ Steen Lindkær-Jensen ${ }^{5}$ \\ ${ }^{1}$ Centre for Epidemiology and Biostatistics, Norwegian School of Veterinary Science, Oslo, Norway \\ ${ }^{2}$ Division of Medical Oncology, Faculty of Medicine, Siriraj Hospital, Mahidol University, Bangkok, Thailand \\ ${ }^{3}$ Department of Oncology, National Taiwan University Hospital, Taiwan \\ ${ }^{4}$ Division of Surgical Oncology, Faculty of Medicine, Udayana University, Sanglah Hospital, Bali, Indonesia \\ ${ }^{5}$ Department of Surgery and Cancer, Hammersmith Hospital Campus, Imperial College, UK
}

\begin{abstract}
An anti-cancer agent containing benzene-poly-carboxylic acids complex with cis-diammineplatinum (II) dichloride (BP-C1) was developed to establish a low toxic and cost effective treatment of breast cancer. The study was aimed to investigate if BP-C1 could be given continuously without rest periods and to estimate Maximum Tolerated (MTD) and Minimum Efficient Dose (MED) in metastatic breast cancer (MBC) treatment. A non-randomized, multicentre trial with 3-level Response Surface Pathway design was performed. Five MBC patients were included at each of the three design levels. BP-C1 was daily administrated intramuscularly during 32 days. The first five patients were given a cumulative dose of $0.64 \mathrm{mg} / \mathrm{kg}$ bodyweight. Based on the obtained results, the dose was increased /decreased for the next five patients in the next design level. The main variable was the National Cancer Institute Common Toxicity Criteria (NCI-CTC). Cumulative doses of $0.96 \mathrm{mg} / \mathrm{kg}$ or higher were defined as high-dose. One moderate and one mild increase in maximum NCI-CTC were found on $0.64 \mathrm{mg} / \mathrm{kg}$, one mild increase occurred on $0.96 \mathrm{mg} / \mathrm{kg}$ and no changes were detected on $1.12 \mathrm{mg} / \mathrm{kg}$. The Sum NCI-CTC increased $(\mathrm{p}=0.07)$ in the low-dose group, but reduced $(\mathrm{p}=0.09)$ in the high-dose group. In the high-dose group, $62.5 \%$ of the patients were classified as responders including one complete responder compared to $28.6 \%$ in the low-dose group. In conclusion, BP-C1 can safely be administrated continuously during 32 days. The MTD is larger than $1.12 \mathrm{mg} / \mathrm{kg}$ and MED estimated to $0.96 \mathrm{mg} / \mathrm{kg}$.
\end{abstract}

Keywords: Benzene-poly-carboxylic acids complex with cis-diammineplatinum (II) dichloride, dose-response, response surface pathway design, MBC and phase I study.

\section{INTRODUCTION}

Chemotherapy remains one of the most important treatment modality in metastatic breast cancer. Platinum compounds are today commonly used in the treatment of solid tumours. The use of platinum compounds has increased in the treatment of breast cancer since cisplatin and monoclonal trastuzumab are reported provide a larger response rate than that expected with either agent alone in heavily pre-treated metastatic breast cancer patient $[1,2]$. The main limitation in the use of platinum compounds is their toxicity. Stage IV breast cancer patients often have to undergo several chemotherapies with severe side effects and toxicity. Shortening or removing the time interval between each chemotherapy cycle while maintaining the same dose size resulted in a significant improvement of the efficacy without increasing the toxicity. In the third world, breast

*Address correspondence to this author at the Centre for Epidemiology and Biostatistics Norwegian School of Veterinary Science, Ullevålsveien 72 P.O. Box 8146 Dep. N-0033 Oslo, Norway; Tel: +4722597098; Fax: +4722597488; E-mails: gitaewi@yahoo.com, gitaewi@gmail.com cancer is characterised by late presentation, occurrence at relatively young ages and dismal mortality rates.

A novel anticancer compound, known as BP-C1 is classified as an anti-cancer category 2 compound and is administered intramuscularly (IM) in order to establish a cost effective treatment. BP-C1 was not developed as a new form of cisplatin administration, but as a new anticancer complex where cisplatin, the carrier molecule and the interaction have their own effects. Due to this and its very low toxicity in preclinical studies, BP-C1 might also be very suitable in the treatment of patients from the $3^{\text {rd }}$ world.

BP-C1 has shown good potential in the preclinical phase. Furthermore, the results, from an unpublished Danish pilot study performed on Stage IV ductal breast cancer patients, indicate good tolerability combined with a good effect.

BP-C1 is a benzene-poly-carboxylic acids complex with cis-diammineplatinum (II) dichloride. This is a polymer complex of carbonic and oxicarbonic acids rich in carboxylgroups replacing the chlorine ions. Through the reaction with platinum, a cis-configuration diamino-dicarboxylate complex is formed. These carboxyl groups, being a part of a complex organic compound, are bound to platinum more 
tightly than the chlorine ions, and have a positive impact on toxicity of the compound compared to cisplatin and carboplatin. BP-C1 is thought to act in the same way as other platinum compounds, which are known to be able to react with DNA to form intra- and interstrand crosslink $[3,4]$. The results from an in vitro project investigating the growth inhibitory effects and cytotoxic time courses of cisplatin, carboplatin and BP- $\mathrm{C} 1$ validate BP-C1 almost as efficient as cisplatin and significantly more efficient than carboplatin [unpublished report, by Christina WY. Effect of BP-C1, Cisplatin and Carboplatin on Growth Cell Death and Intracellular Signalling in The Antiestrogen Sensitive Human Breast Cancer Cell Line MCF-7 and MCF-7 sublines with Acquired Resistance to Antiestrogen Part I: Growth Inhibitory Effects and Cytotoxic Time Course of BP-C1, Cisplatin and Carboplatin 2008]. In another in vitro study, the effect of BP-C1 on growth of human breast cancer cells, MCF7 and T47D was investigated. The results indicated that BP-C1 reduced cell viability of human cancer cells by induction of apoptosis through activation of the extrinsic (death receptors) and the intrinsic (mitochondrion) apoptotic pathways [submitted for publication, by Fuad F, Azzam N, Fares B, Larsen S, Lindkaer-Jensen S. BP-C1, a novel anticancer agent, inhibits human breast cancer cell growth by initiating the extrinsic and the intrinsic apoptosis pathways. 2013]. A pharmacokinetic (PK) study of BP-C1 performed on a dog suffering from mammary cancer showed that the PK fits a 2-compartment model. After one single injection, the maximum concentration (Cmax) was obtained after 15 minutes. The compound was rapidly distributed from the central compartment to the peripheral tissues with a distribution half-life, $\mathrm{T} 1 / 2 \alpha=74$ minutes. The compound was slowly excreted with an elimination half-life, $T 1 / 2 \beta=$ 125.3 hours or 5.2 days. The study might indicate that the compound penetrates the cell membrane and accumulates in the cell [5].

One $\mathrm{ml}$ of BP-C1 contains $0.5 \mathrm{mg}$ of platinumammonium salts of benzene-poly-carboxylic acids, including $0.05 \mathrm{mg}$ of platinum. The predefined cumulative dose window of BP-C1 was given as 0.16 to $1.12 \mathrm{mg} / \mathrm{kg}$ Body Weight (BW) during a maximum treatment period of 32 days. The aims of the present study were (1) to investigate if BP-C1 could be given continuously without rest periods, (2) to estimate the cumulative Maximum Tolerated (MTD) and Minimum Efficient-Dose (MED) in the treatment of metastatic breast cancer patients, and (3) to study the doseresponse pattern related to toxicity and effect.

\section{METHODS}

\section{Population}

The population consisted of Asian female patients between 18 and 80 years of age suffering from histological verified breast cancer with metastases, classified as infiltrating ductal carcinoma, pathological or clinical M1, who previously had undergone third line chemotherapy, hormonal or antibody therapy. Patients with verified metastasis to the brain, significant abnormal liver or kidney functions, haematological status or coagulation capacity were excluded.

\section{Study Sample and Patient Characteristics}

A total of 15 Asian patients suffering from stage IV breast cancer were included in the study. Nine patients were treated at Sanglah Hospital, Udayana University in Bali, Indonesia, three at the National Taiwan University Hospital, Taipei, Taiwan and three at Siriraj Hospital, Mahidol University Bangkok, Thailand. Patients receiving a cumulative dose between 0.64 and $0.88 \mathrm{mg} / \mathrm{kg} / \mathrm{BW}$ were defined as the low-dose group and the patients receiving a cumulative dose from 0.96 to $1.12 \mathrm{mg} / \mathrm{kg} / \mathrm{BW}$ as the highdose group.

The mean age and body weight were 51 years (range: 37 - 67 years) and $57.3 \mathrm{~kg}$ (range: $45.3-78.0 \mathrm{~kg}$ ) respectively. The patients underwent three to nine chemotherapy treatment sequences without known effect. This varied from anthracycline alone and in combination with taxane or platinum compound, cyclophosphamide, cyclophosphamidedoxorubicin- fluorouracil, cyclophosphamide- epirubicinfluorouracil, taxane - platinum compound, vinorelbine tartrate, taxane-flurouracyl, gemcitabine-platinum compound, capecetabine, etoposide, and tegafur-uracil. The mean disease duration was 5.2 years (range: $0.7-18.4$ years). One to seven nodules metastases were reported in 10 patients. In the remaining five, uncountable or multiple metastases were recorded. Seven patients were observed with liver metastases, 6 with lung metastases, 1 having lung and liver metastases and 1 was found to have multiple bone metastases. The study was approved by the Ethical committees and the Medical Agencies in the participating countries. All the patients gave their written consent to participate in the study.

\section{Drop-Outs}

A further three patients were included in the study, but were discontinued due to reasons not related to the trial medication. The first was discontinued after 3 days of treatment due to rapidly progression of diseases and the patient passed away 4 days later. The second patient had metastases to the lung and skin/neck. She discontinued after 14 days of treatment due to the progression of the neck lesion and passed away 42 days later. The third drop-out had multiple bone and liver metastasis and was discontinued after 19 days of treatment. The reason of discontinuation was a bone fracture which meant that a surgical procedure had to be performed.

The study group and the drop-outs were similar with regard to all the observed demographic factors, history of disease and previous cancer treatments.

\section{Study Design}

The study was performed as an open, non-randomized multi-centre trial with a between patient 3-level Response Surface Pathway (RSP) design [submitted for publication, by Dewi S, Kristiansen V, Lindkær-Jensen S, Larsen S. Response surface pathway design in dose response studies. 2013]. The design consists of three design levels and the dose used on the next design level is based on the response obtained on the previous design level. The adjustment of the dose from one design level to the next is based on a k-factor 
estimated to ensure all the doses in the predefined dose window to be possible for use in the study. One patient sequence consists of one patient on each of the three design levels. The first patient in the sequence will be given the mid dose of the predefined cumulative dose window, being equal to $0.64 \mathrm{mg} / \mathrm{kg} / \mathrm{BW}$, representing a dose of $0.02 \mathrm{mg} / \mathrm{kg} / \mathrm{BW}$ in one daily syringe for 32 days. If this patient obtains none/mild or moderate increase in toxicity from baseline, the dose to be used for the second patient in the sequence will be increased. In case this increase in toxicity is severe or larger, the dose will be reduced. The size of the escalation and deescalation of the doses is given by the design and the kfactor (Table 1). If the increase in toxicity score from screening to end of treatment was classified as none or mild, the second patient in the sequence was allocated to a cumulative dose of $0.96 \mathrm{mg} / \mathrm{kg} / \mathrm{BW}$ (Table 1). If the increase in toxicity score was moderate, the cumulative dose was set to $0.80 \mathrm{mg} / \mathrm{kg} / \mathrm{BW}$. In case of severe or life threatening increase, the cumulative dose was reduced to 0.48 $\mathrm{mg} / \mathrm{kg} / \mathrm{BW}$ and $0.32 \mathrm{mg} / \mathrm{kg} / \mathrm{BW}$, respectively. Determination of the dose for the third patient in the sequence will be performed in the same way but based on the results obtained on the second patient.

Five independent sequences, each comprising three patients, were conducted. The tolerability of the treatment was monitored continuously and the toxicity score recorded every eight days and two days after the last injection.

\section{Study Procedure}

During a screening phase of maximum 21 days, clinical investigation and blood sampling were performed. Computed Tomography (CT) of chest and abdomen was performed and described by the locally responsible radiologist. In case of suspected brain metastases, Magnetic Resonance Imaging (MRI) was performed. Additionally, the National Cancer Institute Common Toxicity Criteria (NCI-CTC) Bethesda version 2.0, Karnofsky Performance Scale (KPS) and Patient Well-being (PW) were registered. PW was subjectively scored by the Investigator as "Bad", "Fair" "Good" and "Very Good". Patients who fulfilled the inclusion and met the exclusion criteria entered the study and were examined every eight days during the treatment, as well as two days and four weeks after the last injection. At each visit, the NCI-CTC Bethesda, KPS and PW scores were registered and blood samples were collected. A new CT of chest and abdomen was performed at the final examination, four weeks after the end of the treatment.

\section{Primary Variables}

The main variable in this study was NCI-CTC Bethesda version 2.0 [6]. This includes a total of 91 items of which each is classified as: " $1=$ none or mild", " $2=$ moderate", " $3=$ severe" and " $4=$ Life threatening". From the NCI-CTC Bethesda, the score of the highest single item, called Maximum NCI-CTC Bethesda (Max NCI-CTC), was recorded. This was the main variable in the study together with the sum of NCI-CTC Bethesda scores (Sum NCI-CTC). The change in Max NCI-CTC from the screening to two days after the last injection was used as the classification criteria in the study design. Additionally, spontaneously reported adverse events (AEs) were recorded.

\section{Secondary Variables}

The secondary variables related to the treatment effects were the numbers and the total size of the three largest metastases measured using the Response Evaluation Criteria In Solid Tumours (RECIST) [7]. Additionally, KPS [8] and PW were observed.

Table 1. Pattern of Changes in Cumulative Dose in the Three Levels Response Surface Pathway Design

\begin{tabular}{|c|c|c|c|c|}
\hline Dose on Design Level 1 & $\begin{array}{l}\text { Adverse Events Obtained } \\
\text { on Design Level } 1\end{array}$ & Dose on Design Level 2 & $\begin{array}{l}\text { Adverse Events Obtained } \\
\text { on Design Level } 2\end{array}$ & Dose on Design Level 3 \\
\hline \multirow{16}{*}{$\begin{array}{c}\mathrm{m} \\
(0.64 \mathrm{mg} / \mathrm{kg} / \mathrm{BW})\end{array}$} & \multirow{4}{*}{ None/Mild (1) } & \multirow{4}{*}{$\begin{array}{l}\mathrm{m}+\mathrm{m} / \mathrm{k} \\
(0.96 \mathrm{mg} / \mathrm{kg} / \mathrm{BW})\end{array}$} & None/Mild & $\mathrm{m}+\mathrm{m} / \mathrm{k}+\mathrm{m} / \mathrm{k}^{2}(\mathbf{1 . 1 2} \mathrm{mg} / \mathrm{kg} / \mathbf{B W})$ \\
\hline & & & Moderate & $m+m / k+m / k^{3}(1.04 m g / k g / B W)$ \\
\hline & & & Severe & $\mathrm{m}+\mathrm{m} / \mathrm{k}-\mathrm{m} / \mathrm{k}^{3}(\mathbf{0 . 8 8 m g} / \mathrm{kg} / \mathbf{B W})$ \\
\hline & & & Life threatening & 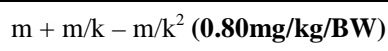 \\
\hline & \multirow{4}{*}{ Moderate (2) } & \multirow{4}{*}{  } & None/Mild & $\mathrm{m}+\mathrm{m} / \mathrm{k}^{2}+\mathrm{m} / \mathrm{k}^{3}(\mathbf{0 . 8 8 m g} / \mathbf{k g} / \mathbf{B W})$ \\
\hline & & & Moderate & $\mathrm{m}+\mathrm{m} / \mathrm{k}^{2}+\mathrm{m} / \mathrm{k}^{4}(\mathbf{0 . 8 4 m g} / \mathrm{kg} / \mathbf{B W})$ \\
\hline & & & Severe & $m+m / k^{2}-m / k^{4}(0.76 m g / k g / B W)$ \\
\hline & & & Life threatening & $m+m / k^{2}-m / k^{3}(0.72 m g / k g / B W)$ \\
\hline & \multirow{4}{*}{ Severe (3) } & \multirow{4}{*}{ 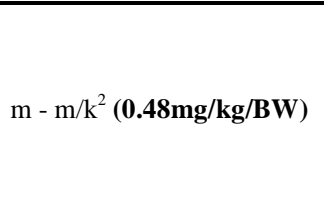 } & None/Mild & $\mathrm{m}-\mathrm{m} / \mathrm{k}^{2}+\mathrm{m} / \mathrm{k}^{3}(\mathbf{0 . 5 6 m g} / \mathrm{kg} / \mathbf{B W})$ \\
\hline & & & Moderate & $m-m / k^{2}+m / k^{4}(0.52 m g / k g / B W)$ \\
\hline & & & Severe & $m-m / k^{2}-m / k^{4}(0.44 m g / k g / B W)$ \\
\hline & & & Life threatening & 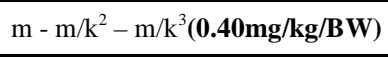 \\
\hline & \multirow{4}{*}{ Life threatening (4) } & \multirow{4}{*}{$\mathrm{m}-\mathrm{m} / \mathrm{k}(\mathbf{0 . 3 2} \mathrm{mg} / \mathbf{k g} / \mathbf{B W})$} & None/Mild & $\mathrm{m}-\mathrm{m} / \mathrm{k}+\mathrm{m} / \mathrm{k}^{2}(\mathbf{0 . 4 8} \mathrm{mg} / \mathrm{kg} / \mathbf{B W})$ \\
\hline & & & Moderate & $\mathrm{m}-\mathrm{m} / \mathrm{k}+\mathrm{m} / \mathrm{k}^{3}(\mathbf{0 . 4 0 m g / k g / B W})$ \\
\hline & & & Severe & $\mathrm{m}-\mathrm{m} / \mathrm{k}-\mathrm{m} / \mathrm{k}^{3}(\mathbf{0 . 2 4 m g} / \mathrm{kg} / \mathbf{B W})$ \\
\hline & & & Life threatening & $\mathrm{m}-\mathrm{m} / \mathrm{k}-\mathrm{m} / \mathrm{k}^{2}(\mathbf{0 . 1 6 m g} / \mathrm{kg} / \mathbf{B W})$ \\
\hline
\end{tabular}




\section{Classification of Effect Response}

The treatment response was classified as "Complete response (CR)", "Partial response (PR)", "Stable disease (SD)" or "Progressive disease (PD)" [7].

Patients obtaining $\mathrm{SD}, \mathrm{PR}$ or $\mathrm{CR}$ were defined as responders to the treatment after a confirming CT one month after the last treatment day.

\section{Maximum Tolerated and Minimum Efficient Doses}

The MTD was defined as the lowest cumulative dose obtaining severe toxicity with a probability larger or equal to $1 / 3$. The MED was defined as the lowest cumulative dose with at least $50 \%$ positive response probability.

\section{Statistical Analysis}

Assumed continuously distributed variables were expressed by mean values with $95 \%$ confidence intervals [9]. Standard Deviation (SD) was used for the expression of dispersion. In the case of unimodal skewed distribution, the data were logarithmically transformed before performing the analysis. The results were retransformed for presentation.

The MTD was supposed to be estimated by using isotonic regression [10]. Time to event was analysed using a Survival model and expressed by median with $95 \%$ confidence interval [11]. Categorised and discontinuously distributed variables were expressed in contingency tables and analysed using a Contingency Table Analysis [12]. The change in toxicity during the treatment was handled as a categorical variable, but was also graphically shown in a response surface pathway plot. All the comparisons were performed two-tailed and differences were considered significant if the p-value was less or equal to $5 \%$. Comparison between and changes within groups, with regard to assumed continuously distributed variables, were performed using Analysis of Variance (ANOVA) [13].

\section{RESULTS}

\section{Toxicity}

The Max NCI-CTC was initially classified as "Severe" in one, "Moderate" in 10 and "None to mild" in the remaining four patients. Three of the five patients receiving 0.64 $\mathrm{mg} / \mathrm{kg} / \mathrm{BW}$ on the first design level had unchanged Max NCI-CTC score two days after the end of the treatment, as shown in Fig. (1). One patient reported mild and one reported moderate increase in Max NCI-CTC. Consequently, four patients on the second design level received a cumulative dose of $0.96 \mathrm{mg} / \mathrm{kg} / \mathrm{BW}$ and one 0.80 $\mathrm{mg} / \mathrm{kg} / \mathrm{BW}$. Of the four patients receiving $0.96 \mathrm{mg} / \mathrm{kg} / \mathrm{BW}$, three obtained no change in Max NCI-CTC and one patient obtained a mild increase. The Max NCI-CTC in the patient receiving $0.80 \mathrm{mg} / \mathrm{kg} / \mathrm{BW}$ was found unchanged, as shown in Fig. (1). Based on these results, four patients on the third design level were given the maximum cumulative dose of $1.12 \mathrm{mg} / \mathrm{kg} / \mathrm{BW}$ without obtaining any change in Max NCICTC. The remaining patient receiving $0.88 \mathrm{mg} / \mathrm{kg} / \mathrm{BW}$ and the Max NCI-CTC did not exhibit any change.

The development in Max NCI-CTC from the screening to the end of follow-up indicated the largest toxicity increase in the patients on the first design level and smallest on the third design level. Of the five patients receiving $0.64 \mathrm{mg} / \mathrm{kg} / \mathrm{BW}$, two were found unchanged, two with mild increase and one with severe increase in Max NCI-CTC. Three of the four patients receiving $0.96 \mathrm{mg} / \mathrm{kg} / \mathrm{BW}$ at the second design level had an unchanged maximum toxicity score and one had a mild increase. The patient receiving $0.80 \mathrm{mg} / \mathrm{kg} / \mathrm{BW}$ on the second design level had a moderate increase at the end of follow-up. Of the four patients receiving $1.12 \mathrm{mg} / \mathrm{kg} / \mathrm{BW}$ at the third design level, three had unchanged maximum toxicity and one had a mild increase.

The Sum NCI-CTC increased nearly significantly $(\mathrm{p}=0.07)$ from $6.9(95 \% \mathrm{CI}: 1.4-12.3)$ to 9.6 (95\% CI: $4.4-$ 14.7) during the treatment and further to 12.4 (95\% CI: $6.5-$ 18.3) at the end of follow-up in the low-dose group, as shown in Fig. (2). In the high dose group, the Sum NCI-CTC was reduced $(\mathrm{p}=0.09)$ from $7.3(95 \% \mathrm{CI}: 4.0-10.2)$ to 6.0 (95\% CI: $4.6-7.4)$ during the treatment. The cumulative dose of BP-C1 was negatively and significantly correlated with the increase in toxicity $(\mathrm{r}=-0.52 ; \mathrm{p}=0.048)$ and alone explained the $27 \%$ of the variation. Together with the baseline Sum NCI-CTC, the cumulative dose explained 43 $\%$ of the variation in the toxicity increase. The Sum NCICTC was parallel and nearly constant in the two groups during the first 16 days of the treatment. Thereafter, the toxicity increased in the low-dose group but decreased in the high-dose group, as shown in Fig. (2). The difference between the groups in the development of Sum NCI-CTC was not significant $(\mathrm{p}=0.11)$.

Seven patients in the low-dose group reported 12 mild and one moderate AEs, which might be related to treatment. Eight patients in the high-dose group reported 22 mild and three moderate AEs. The difference in prevalence of $\mathrm{AE}$ between the groups was not significant $(p=0.06)$. The duration of AE was significantly longer $(\mathrm{p}<0.01)$ in the highdose compared to the low-dose group. The median time to occurrence of AE was 13 days (95\% CI: 2 - 18) in the lowdose group compared to 16 days $(95 \% \mathrm{CI}: 8-24)$ in the high-dose group $(\mathrm{p}=0.03)$.

\section{Efficacy}

The number of metastases increased at the end of followup in two of the seven patients in the low-dose group and remained unchanged in the remaining five. In the high-dose group, the number of metastases increased in two patients, remained unchanged in four and was reduced in two patients. One of these two patients was classified as CR in which none of the six metastases in the lung detected at the initial screening was found at the CT performed at the end of the follow-up. In the high-dose group, four patients received a cumulative dose of $0.96 \mathrm{mg} / \mathrm{kg} / \mathrm{BW}$ and four 1.12 $\mathrm{mg} / \mathrm{kg} / \mathrm{BW}$. Fifty per cent of the patients treated with 0.96 $\mathrm{mg} / \mathrm{kg} / \mathrm{BW}$ and $75 \%$ with $1.12 \mathrm{mg} / \mathrm{kg} / \mathrm{BW}$ were classified as responders (Table $\mathbf{2}$ ).

The response rate in the high-dose group was $62.5 \%$ compared to $28.6 \%$ in the low-dose group. The mean sum of the longest diameters of the three largest metastases increased slightly from $53.7 \mathrm{~mm}(95 \% \mathrm{CI}: 3.9$ - 103.5) to $55.5 \mathrm{~mm}(95 \% \mathrm{CI}: 5.7-105.3)$ at the end of follow-up in the low-dose group. In the high-dose group, the sum of the longest diameters was reduced from $64.5 \mathrm{~mm}$ (95\% CI: 52.4 - 76.5) to $54.9 \mathrm{~mm}(95 \% \mathrm{CI}: 27.4-83.0)$ at the end of follow-up. 
Design level 1

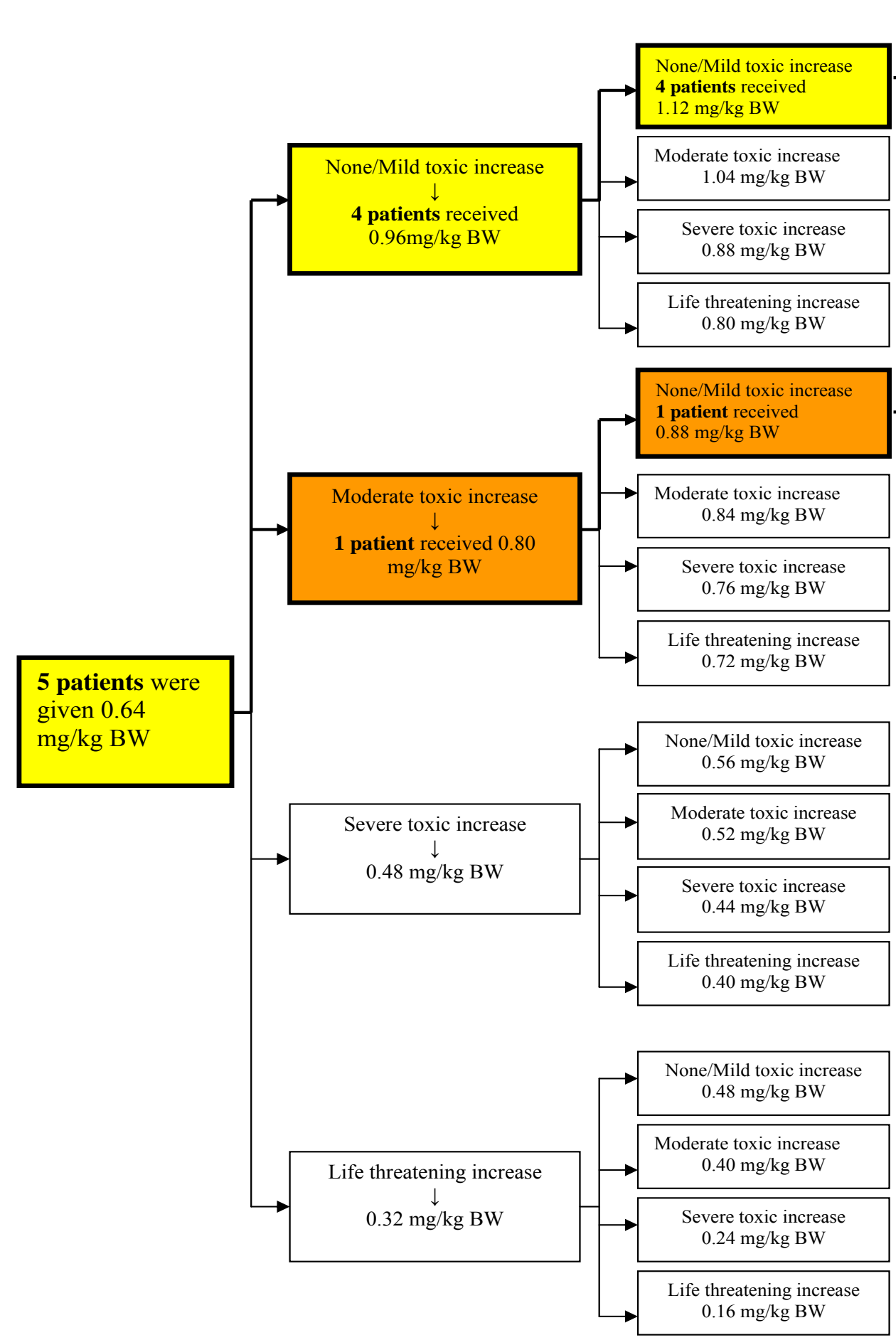

Fig. (1). The three levels between patients Response Surface Pathway Design presenting the possible dose pathways and the obtained results in the five treatment sequences with three patients in each.

The KPS was recorded as 70 in two patients, 80 in eight patients and 90 in five patients. The low- and high-dose groups had similar KPS at the screening. The low- and highdose groups were similar at the screening. At the end of treatment, the development in KPS was clearly better in the high-dose group compared to the low-dose (Table 3). The reduction in KPS from screening to the end of follow-up was significant $(p<0.01)$ in the low-dose group but nearly unchanged in the high-dose group. 


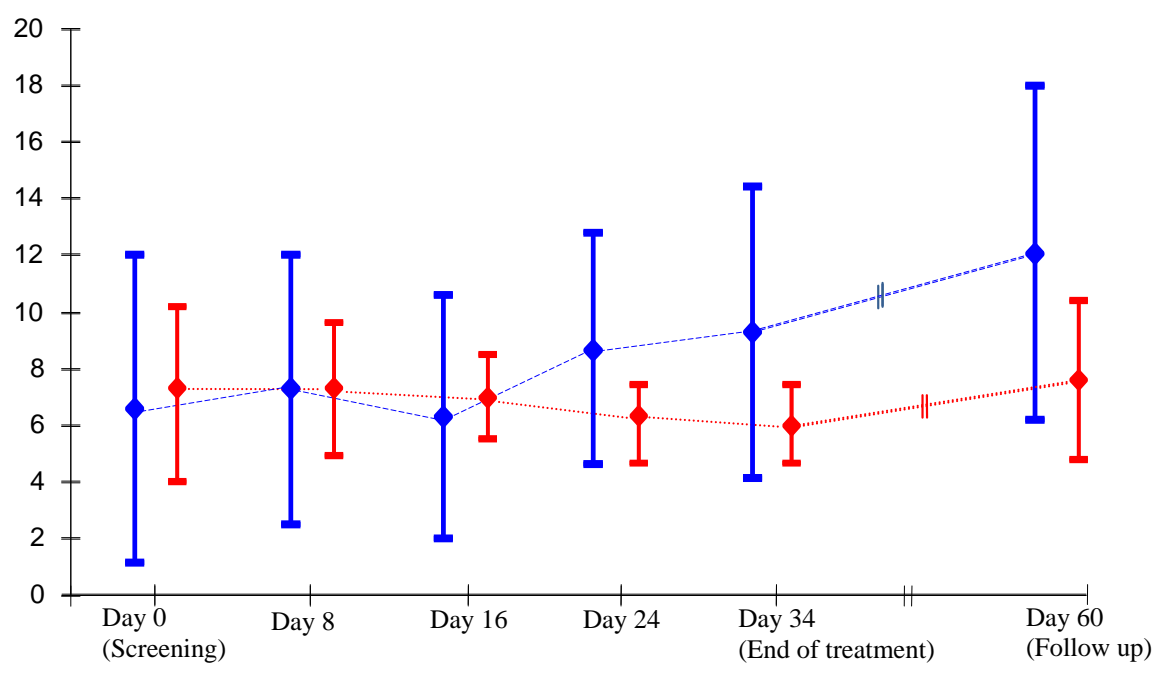

Fig. (2). The development in the sum of NCI Bethesda score during the 32 days of treatment and the end of follow-up 28 days after the last injection divided in the low- and high-dose groups. The results are expressed as mean values with $95 \%$ confidence intervals given as bars. The red bold bars represent the high-dose group and the blue bars the low-dose.

At screening, the PW was classified as "Fair" for three patients and "Good" for the remaining 12. Initially, the lowand high-dose groups were similar. The PW was reduced in five of the seven patients from screening to the end of follow-up in the low-dose group ( $\mathrm{p}=0.03)$. In the high-dose group, one patient had reduced and two patients were found to have increased the PW.

The laboratory variables related to red blood cells showed positive development during the treatment and follow-up in both groups, but were significantly pronounced in the high-dose group (Table 4). The platelet counts were slightly reduced in both dose groups during the treatment and the follow-up but thrombocytopenia did not occur. The leucocytes developed positively in both dose groups during the treatment and the follow-up. In the high-dose group, the leucocytes increased significantly from screening to the end of the treatment $(p<0.01)$ and to the end of follow-up $(\mathrm{p}=0.03)$. Gamma-glutamyl transpeptidase (Gamma-GT), alanine aminotransferase (ALAT) and bilirubin increased in the low-dose group but were reduced or remained constant in the high-dose group (Table 4). Lactate dehydrogenase (LDH) showed a similar pattern, whereas albumin was nearly unchanged in both groups.

Blood urea nitrogen (BUN) increased significantly $(p=0.02)$ during the treatment in the low-dose group, but only a slight, insignificant, increase was detected in the highdose group. The C Reactive Protein (CRP) increased in both groups during the treatment. The increase in CRP from screening to the end of follow-up was significant $(p=0.03)$ in the high-dose group.

Table 2. Classification of Response in Accordance with the RECIST Criteria Divided on Low and High Dose

\begin{tabular}{|c|c|c|c|c|c|}
\hline Dose Level & Complete Responder & Partial Responder & Stable Disease & Progressive Disease & Total \\
\hline Low dose $(0.64-0.88 \mathrm{mg} / \mathrm{kg} \mathrm{BW})$ & 0 & 1 & 1 & 5 & 7 \\
\hline Total Number & 1 & 2 & 4 & 8 & 15 \\
\hline
\end{tabular}

Table 3. Change in Karnofsky Performance Scale (KPS) from Screening to End of Treatment and End of Follow-Up in the Lowand High-Dose Groups

\begin{tabular}{|c|c|c|c|c|c|c|c|}
\hline & Dose Group & \multicolumn{6}{|c|}{ Change in Karnofsky Performance Scale } \\
\hline End of treatment & High dose $(0.96-1.12 \mathrm{mg} / \mathrm{kg} \mathrm{BW})$ & 0 & 0 & 0 & 0 & 7 & 1 \\
\hline End of follow-up & Low dose $(0.64-0.88 \mathrm{mg} / \mathrm{kg} \mathrm{BW})$ & 2 & 1 & 0 & 2 & 2 & 0 \\
\hline
\end{tabular}


Table 4. Increase in the Laboratory Variables from Screening to End of Treatment and End of Follow-Up in the Low- and HighDose Group

\begin{tabular}{|c|c|c|c|c|}
\hline \multirow{2}{*}{ Type of Analysis } & \multirow{2}{*}{ Laboratory Variables } & \multirow{2}{*}{ Dose Group } & \multicolumn{2}{|c|}{ Increase in Laboratory Variables } \\
\hline & & & During Treatment & End of Follow-Up \\
\hline \multirow{18}{*}{ Haematology } & \multirow[t]{2}{*}{ Haemoglobin $(\mathrm{g} / \mathrm{dl})$} & Low-dose & $0.8(0.1-1.5)$ & $0.7(-0.3-1.7)$ \\
\hline & & High-dose & $0.6(-0.2-1.4)$ & $0.2(-0.7-1.1)$ \\
\hline & \multirow[t]{2}{*}{ Erythrocytes $\left(10^{5} \mu \mathrm{L}\right)$} & Low-dose & $0.26(0.04-0.47)$ & $0.38(-0.20-0.95)$ \\
\hline & & High-dose & $0.05(-0.72-0.82)$ & $0.33(0.03-0.63)$ \\
\hline & \multirow[t]{2}{*}{ Pack cell volume $(\%)$} & Low-dose & $1.1(-0.8-3.0)$ & $0.8(-3.9-5.6)$ \\
\hline & & High-dose & $2.4(0.4-4.4)$ & $1.4(-1.6-4.4)$ \\
\hline & \multirow[t]{2}{*}{ Mean Cell Volume (fL) } & Low-dose & $-3.2(-5.9--0.5)$ & $-6.5(-8.4--4.7)$ \\
\hline & & High-dose & $-2.6(-5.6-0.4)$ & $-5.5(-9.5--1.5)$ \\
\hline & \multirow[t]{2}{*}{ Ferritin $(\mathrm{ng} / \mathrm{ml})$} & Low-dose & $154(-1-310)$ & $506(30-981)$ \\
\hline & & High-dose & $20(-191-230)$ & $165(-318-649)$ \\
\hline & \multirow[t]{2}{*}{ Thrombocytes $10^{3} \mu$} & Low-dose & $-21(-101-58)$ & $11(-82-105)$ \\
\hline & & High-dose & $-31(-113-51)$ & $-17(-104-69)$ \\
\hline & \multirow[t]{2}{*}{ Leucocytes $\left(10^{9} / \mathrm{L}\right)$} & Low-dose & $1.2(-1.5-3.9)$ & $2.7(-1.1-6.5)$ \\
\hline & & High-dose & $1.6(0.6-2.6)$ & $1.3(0.2-2.4)$ \\
\hline & \multirow[t]{2}{*}{ Monocytes (\%) } & Low-dose & $-1.4(-4.5-1.6)$ & $-1.7(-4.0-0.7)$ \\
\hline & & High-dose & $-1.6(-3.6-0.4)$ & $-1.6(-3.9-0.7)$ \\
\hline & \multirow[t]{2}{*}{ Lymphocytes } & Low-dose & $-0.9(-10.0-8.1)$ & $-8.4(-18.5-1.8)$ \\
\hline & & High-dose & $-5.1(-11.8-1.5)$ & $-6.7(-10.9-2.5)$ \\
\hline \multirow{18}{*}{ Biochemistry } & \multirow[t]{2}{*}{ Gamma GT (U/L) } & Low-dose & $46.9(-10.4-104.3)$ & $44.5(-17.6-106.6)$ \\
\hline & & High-dose & $19.4(-24.9-63.8)$ & $19.3(-31.4-70.1)$ \\
\hline & \multirow[t]{2}{*}{ Lactate dehydrogenase (U/L) } & Low-dose & $612(-156-1379)$ & $944(-1042-2931)$ \\
\hline & & High-dose & $-20(-185-145)$ & $99(-116-314)$ \\
\hline & \multirow[t]{2}{*}{ Alkaline phosphatase (U/L) } & Low-dose & $-7.5(-98.5-83.5)$ & $9.1(-91.8-110)$ \\
\hline & & High-dose & $45.8(-34.7-126.4)$ & $78.6(-94.8-248.0)$ \\
\hline & \multirow[t]{2}{*}{ Albumin $(\mathrm{g} / \mathrm{dl})$} & Low-dose & $-0.06(-0.67-0.55)$ & $-0.53(-1.41-0.34)$ \\
\hline & & High-dose & $0.07(-0.07-0.20)$ & $0.02(-0.54-0.58)$ \\
\hline & \multirow[t]{2}{*}{ Bilirubin (mg/dl) } & Low-dose & $0.15(-0.21-0.51$ & $0.24(-0.05-0.54)$ \\
\hline & & High-dose & $-0.16(-0.44-0.13)$ & $-0.06(-0.37-0.26)$ \\
\hline & \multirow[t]{2}{*}{$\operatorname{ALAT}(\mathrm{U} / \mathrm{L})$} & Low-dose & $11.5(-4.0-27.1)$ & $19.8(-14.6-54.2)$ \\
\hline & & High-dose & $-1.8(-8.1-4.6)$ & $-1.8(-9.9-6.3)$ \\
\hline & \multirow[t]{2}{*}{ Urea $(\mathrm{mg} / \mathrm{dl})$} & Low-dose & $6.1(2.0-10.2)$ & $9,6(-5.0-24.2)$ \\
\hline & & High-dose & $5.1(-0.7-10.8)$ & $1.6(-2.4-5.6)$ \\
\hline & \multirow[t]{2}{*}{ Creatinin (mg/dl) } & Low-dose & $-0.06(-0.10-0.0)$ & $-0.07(-0.19-0.06)$ \\
\hline & & High-dose & $0.10(-0.02-0.22)$ & $0.13(-0.03-0.29)$ \\
\hline & \multirow[t]{2}{*}{ C Reactive Protein (mg/dl) } & Low-dose & $1.1(-1.5-3.7)$ & $2.3(-1.2-5.8)$ \\
\hline & & High-dose & $1.8(-0.1-3.5)$ & $4.9(1.7-8.1)$ \\
\hline
\end{tabular}

\section{DISCUSSION}

The present study demonstrates that BP-C1 can safely be administered IM continuously with one daily injection for 32 days. The cumulative MTD of BP-C1 is most probably higher than $1.12 \mathrm{mg} / \mathrm{kg} / \mathrm{BW}$ and the cumulative MED seems to be $0.96 \mathrm{mg} / \mathrm{kg} / \mathrm{BW}$. The results indicate a positive toxicity and efficacy dose-response.
The route of BP-C1 administration and the treatment schedule are both quite different from those usually used in cancer treatment. The treatment schedule is justified from unpublished preclinical data with BP-C1 in mice and rats. A low dose over a long treatment period was found to give better efficacy and lower toxicity than higher doses over shorter periods. Based on the pre-clinical results, it was decided not to exceed a treatment period of 32 days in humans. Since BP-C1 is 
classified as an anti-cancer category 2 compound, it was decided to administer BP-C1 IM, in order to also establish a cost effective treatment suitable for treatment of patients from the $3^{\text {rd }}$ world. Complex cancer treatments in the $3^{\text {rd }}$ worlds are, in reality, not available [14]. According to Anyanwu, "breast cancer in $3^{\text {rd }}$ world is characterised by late presentation, occurrence at relatively young ages and dismal mortality rates". Such poor prospects have encouraged patients to patronise quacks and alternative healers [14]. Consequently, it is important to develop a cost effective treatment with limited toxicity, which can be used by nurses on an outpatient basis, guided by a physician or oncologist. Considering this, BP-C1 seems likely to a treatment candidate.

To reduce the toxicity of anti-cancer drugs, it is common to increase the rest period but to maintain the recommended treatment dose. Another strategy is to reduce the treatment dose, but maintain the duration of the rest period. Both of these strategies might succeed in reduction of the toxicity but they simultaneously reduce efficacy of the treatment [15]. A dose dense approach could improve both the overall effect of therapy and the patient survival rate [16]. The preclinical data for BP-C1 did not support continuous use of the compound over 32 days. In spite of the relatively small number of patients, the present results clearly demonstrate that treatment duration of 32 days, even with the predefined upper limit of the cumulative dose, appears to be safe.

Usually such kind of dose-response studies are performed at one University hospital and may result in data not representative for the population in question. The aim of this study was to estimate MED and MTD in the Asian population and was therefore performed as an international multicenter study including patients from all the three countries. The deviation in the data will obviously increase but give more representative results.

Based on the preclinical results, the cumulative dose window of $\mathrm{BP}-\mathrm{C} 1$ in human was quite wide. It was therefore decided to use a starting dose in the middle of the range. It had been suggested that the starting dose should be linked to the $\mathrm{LD}_{10}$ of the drug [17]. Due to the estimated $\mathrm{LD}_{10}$, this strategy was avoided. In line with earlier results, the increase in toxicity was found to be mild. The design pathway of the study, ending up with four of the possible five patients at the upper limit of the interval, resulted in none of these patients reporting increased toxicity during the treatment. The present study was not able to establish the MTD of BP-C1. Most probably the MTD of BP$\mathrm{C} 1$ is higher than the cumulative dose of $1.12 \mathrm{mg} / \mathrm{kg} / \mathrm{BW}$, or a daily dose of $0.035 \mathrm{mg} / \mathrm{kg} / \mathrm{BW}$ given continuously over 32 days. The MTD consists of the daily dose and the duration of treatment. The maximum of both these factors were included without any resulting increase in the toxicity score. New studies, including larger cumulative doses of $\mathrm{BP}-\mathrm{C} 1$, are needed in order to investigate the toxicity dose-response surface. One way would be to keep the treatment period to 32 days while increasing the daily dose from $0.035 \mathrm{mg} / \mathrm{kg} / \mathrm{BW}$. The question is how much this daily dose can be increased since it is already in the upper limit of the predefined dose window. Furthermore, since BP-C1 is to be administered IM it limits the volume of the daily dose. A daily dose of $0.035 \mathrm{mg} / \mathrm{kg} / \mathrm{BW}$ represents $4.2 \mathrm{ml}$ for a patient of $60 \mathrm{~kg}$. In the present study, this dose was used without any problem. Based on clinical knowledge and experience, it can safely be increased to a daily dose of $6 \mathrm{ml}$.
Such an increase will represent a cumulative dose of 1.37 $\mathrm{mg} / \mathrm{kg} / \mathrm{BW}$. Another possibility would be to keep the daily dose at $0.035 \mathrm{mg} / \mathrm{kg} / \mathrm{BW}$, but to increase the treatment duration beyond 32 days. Using a two dimensional, three-level response surface design, the optimal combination of the daily dose and the duration of treatment can be estimated.

The Sum NCI-CTC increased for the patients receiving a cumulative dose of less than or equal to $0.88 \mathrm{mg} / \mathrm{kg} / \mathrm{BW}$, but was reduced for the patients given a dose of $0.96 \mathrm{mg} / \mathrm{kg} / \mathrm{BW}$ or more. Both the cancer itself and BP-C1 contribute to the total toxicity, which explains nearly $50 \%$ of the change in toxicity during the treatment. The observed toxicity recorded at screening seems to be mainly caused by the disease itself. The addition of an assumed toxic drug may increase the toxicity. However, when the anti-cancer drug used is BP-C1, the toxicity declines. This negative correlation between the drug used and the toxicity score might be explained by the effect of BP-C1 on the cancer.

Although the prevalence and the duration of the reported AEs were found increased with the increase in the cumulative dose the time before the occurrence of AEs was found to be longer in the high-dose group which indicates a positive toxicity dose-response.

The development in the Sum NCI-CTC during the treatment was found nearly parallel in the two dose groups for the first 16 days, but diverged in the last 16 days. This would appear to indicate that daily doses below $0.03 \mathrm{mg} / \mathrm{kg} / \mathrm{BW}$ are too low to inhibit the development of metastases in stage IV breast cancer patients. At the end of treatment, only the low-dose patients reported reduced KPS. The difference between the low- and the high-dose groups was found even more pronounced at the end of the follow-up. A similar pattern was detected on the development of the metastases and the change in the PW. The size of the metastases increased in the low-dose group, but was reduced in the high-dose group. PW was found unchanged or increased in nearly all high-dose patients but reduced in more than $70 \%$ of the patients in the low-dose group. The lowest cumulative dose used in the high-dose group was 0.96 $\mathrm{mg} / \mathrm{kg} / \mathrm{BW}$. On this dose, $50 \%$ of the patients were classified as responder to the treatment. Even though the number of patients was small, this was the lowest dose used fulfilling the demand to MED.

The efficacy of BP-C1 was mainly detected in the high-dose group and the results demonstrate significant differences both on tumour size, and in the improvement of the KPS and the PW. A positive relation between the $\mathrm{BP}-\mathrm{C} 1$ dose and the three recorded efficacy variables appears to be quite obvious. The negative correlation between the cumulative dose and the toxicity supports these findings.

The registration of PW performed by investigators was based on the information given by the patients. The detected significant increase of PW during the treatment -might indicate an increase in the quality of life. Quality of Life Questionnaires was not considered in the present study, but is recommended for further studies.

All the recorded haematological variables developed positively during the $\mathrm{BP}-\mathrm{Cl}$ treatment. Contrary to the commonly reported negative $\mathrm{AE}$ with the administration of cisplatinum drugs, thrombocytopenia was not registered in the present study with the administration of BP-C1. Similarly, the 
observed development in neutrophils during the treatment did not exhibit any signs of myelosuppression. Furthermore, the present study did not detect any negative effect on the liver function, even at the highest dose of BP-C1 similar to other platinum compounds. They are generally not classified as hepatotoxic drugs [18]. The increase of Gamma GT and LDH in the low-dose group together with the slight reduction in the high-dose group clearly supports the positive efficacy doseresponse of BP-C1. The CRP increased in both groups during treatment. Elevated CRP levels correlate to SICAM-1, which also reflects the acute phase response and generalised inflammation [19]. Thus, the increase in CRP could reflect tumour cell death caused by BP-C1. The overall evaluation of the laboratory results obtained during the $\mathrm{BP}-\mathrm{Cl}$ treatment was positive.

However, since the present study was only designed to determine short-term toxicity and not mid or long-term toxicity, another Phase I study to determine the optimal duration and cumulative dose of BP-C1 in breast cancer patients with distant metastases must be conducted. This seems of particular interest, especially since platinum compounds sometimes have significant cumulative toxicity, such as neurotoxicity. Additionally, the effects of the compound need to be further investigated in phase II studies with inclusion of a much larger number of patients. It is known that metabolic differences exist between ethnic groups [20, 21]. Therefore a Phase II study in Caucasian as well as Asian patients must be conducted to investigate if an ethnic difference in treatment efficacy and toxicity of BP-C1 exists.

\section{CONCLUSIONS}

BP-C1 can safely be administrated continuously with one IM injection daily during a period of 32 days. The cumulative MTD of BP-C1 is most probably larger than $1.12 \mathrm{mg} / \mathrm{kg} / \mathrm{BW}$ and the cumulative MED seems to be $0.96 \mathrm{mg} / \mathrm{kg} / \mathrm{BW}$. The results clearly indicate positive dose-response both for toxicity and efficacy.

\section{CONFLICT OF INTEREST}

None of the authors were employed or stockowner in the company. Prof Stig Larsen and Prof Steen Lindkær-Jensen have been consultants for Meabco AS. The company has not participated in writing the protocol or development of the study design, data collection, statistical analysis or interpretation of data and writing or submission of the manuscript for publication.

\section{ACKNOWLEDGEMENTS}

This University Hospital based study was financially supported by Meabco AS, Richard Mortensens vej 61A, DK23000 Copenhagen S, Denmark.

\section{REFERENCES}

[1] Decatris MP, Sundar S, O'Byrne KJ. Platinum-based chemotherapy in metastatic breast cancer: current status. Cancer Treat Rev 2004; 30(1): 53-81.

[2] Pegram MD, Lipton A, Hayes DF, et al. Phase II study of receptorenhanced chemosensitivity using recombinant humanized antip185HER2/neu monoclonal antibody plus cisplatin in patients with HER2/neu-overexpressing metastatic breast cancer refractory to chemotherapy treatment. J Clin Oncol 1998; 16(8): 2659-71.

[3] Knox RJ, Friedlos F, Lydall DA, Roberts JJ. Mechanism of cytotoxicity of anticancer platinum drugs: evidence that cis-diamminedichloroplatinum(II) and cis-diammine-(1,1-cyclobutanedicarboxylato)platinum (II) differ only in the kinetics of their interaction with DNA. Cancer Res 1986; 46(4 Pt 2): 1972-9.

[4] Reed E. Cisplatin and analogs. In: Chabner BA, Longo DL, Eds Cancer Chemotherapy and Biotherapy: Principles and Practice. Philadelphia: Lippincott Williams and Wilkins 2001. pp. 447-65.

[5] Kristiansen V, Dewi S, Jonasdottir T, Larsen S. Toxicity and pharmacokinetic profile of a new anticancer agent in canine mammary cancer. Proceedings of the 2nd World Veterinary Cancer Congress; 2012 March 1-3; Paris, France; p. 20, 2012.

[6] National Cancer Institute. Common Toxicity Criteria (CTC) version 2.0. Available at: http://ctep cancer gov/protocolDevelopment/electr onic_applications/docs/ctcv20_4-30-992.pdf

[7] Therasse P, Arbuck SG, Eisenhauer EA, et al. New guidelines to evaluate the response to treatment in solid tumors. J Natl Cancer Inst 2000; 92(3): 205-16.

[8] Karnofsky DA, Burchenal JH. The clinical evaluation of chemotherapeutic agents in cancer. In: Macleod CM, Ed. Evaluation of Chemotherapeutic Agents. New York: Columbia University Press, ic Agents 1949; pp. 199-205.

[9] Altman DG. Practical Statistic for Medical Research. $1^{\text {st }}$ ed. London: Chapman \& Hall 1991.

[10] Paul RK, Rosenberger WF, Nancy F. Quantile estimation following non-parametric phase I clinical trials with ordinal response. Stat Med 2004; 23(16): 2483-95.

[11] Machin D, Cheung YB, Parmar MKB. Survival Analysis: A Practical Approach. $2^{\text {nd }}$ ed. Chichester: John Wiley and Sons 2006.

[12] Agresti A. Categorical Data Analysis. 2nd ed. New Jersey: John Wiley and Sons 2002.

[13] Kleinbaum DG, Kupper LL, Muller KE, Nizam A. Applied Regression Analysis and Other Multivariable Methods. $2^{\text {nd }}$ ed. Pacific Grove: Duxbury Press 1988.

[14] Anyanwu SN. Temporal trends in breast cancer presentation in the third world. J Exp Clin Cancer Res 2008; 27 : 17.

[15] Chu E, DeVita VT. Physicians' Cancer Chemotherapy Drug Manual 2008. Massachusetts: Jones and Bartlett 2008.

[16] Seidman AD. Current status of dose-dense chemotherapy for breast cancer. Cancer Chemother Pharmacol 2005; 56(Suppl 1): 78-83.

[17] Ivanova A. Dose-Finding in Oncology - Nonparametric Methods. In: Ting Naitee, Ed. Dose Finding in Drug Development. USA: Springer; 2006; pp. 49-58.

[18] Aronson JK. Platinum-containing cytostatic drugs. In: Aronson JK, Ed. Meyler's Side Effects of Drugs: The International Encyclopedia of Adverse Drug Reactions and Interactions. Amsterdam: Elsevier 2006; pp. 2849-72.

[19] Blann AD, Byrne GJ, Baildam AD. Increased soluble intercellular adhesion molecule-1, breast cancer and the acute phase response. Blood Coagul Fibrinolysis 2002; 13(2): 165-8.

[20) Burroughs VJ, Maxey RW, Levy RA. Racial and ethnic differences in response to medicines: towards individualized pharmaceutical treatment. J Natl Med Assoc 2002; 94(10 Suppl): 1-26.

[21] Critchley JA, Nimmo GR, Gregson CA, Woolhouse NM, Prescott LF Inter-subject and ethnic differences in paracetamol metabolism. Br J Clin Pharmacol 1986; 22(6): 649-57. 